\title{
Colour plates
}

\section{Colour plates appear between pages 174 and 175}

1 Map of the regional and national centres

2 OU staff maintaining complex and sensitive data sets

3 The East Midlands regional office

4 OU office, Cardiff

5 The trial of a telewriting system in 1982

6 Professor Colin Pillinger, who led the project to search for signs of life on Mars

7 Lifelong learners do not stop their engagement with the OU, even after graduation

8 Tutor David Heley and OU student Lisa Hubbard play Frank and Rita in a performance of Educating Rita

9 OU students campaigning about funding and library access

10 The OU has always been available to service personnel: in this instance, the RAF

11 An 'Elluminate' online tutorial

12 Mavis Nkwenkwana in East London, South Africa

13 Nelson Mandela accepting an honorary doctorate from Vice-Chancellor Brenda Gourley and Chancellor Betty Boothroyd

14 Emeritus Professor Stuart Hall

15 Martin Bean, Vice-Chancellor, in a Second Life virtual address (courtesy of Rebecca Ferguson)

16 OU students campaigning for grants

17 A poster designed by PhD student Rebecca Ferguson for Schome courtesy of Rebecca Ferguson

18 A tutorial in the $1990 \mathrm{~s}$

19 A ceremonial bonfire of course materials from August 1985 
20 A shot of Olivia Plender's art installation, Rise Early, Be Industrious (2012)

21 Discussion in a tutorial

22 Learning together

23 Studying in the garden

24 OU field trips were often a part of a residential school experience

25 Jacket for the A guide for learners in prison prospectus 